\title{
THEORETICAL APPROACH OF THE CATALYTIC HYDROCHLORINATION OF THE 3-AMINO-2H-1,2,4-TRIAZOLE
}

\author{
Jean Baptiste Mensah ${ }^{1 *}$, Gaston A. Kpotin ${ }^{1}$ and Georges Accrombessi ${ }^{2}$ \\ ${ }^{1}$ Laboratoire de Chimie Théorique et de Spectroscopie Moléculaire (LACTHESMO) 03 BP \\ 3409 Cotonou, Bénin \\ ${ }^{2}$ Laboratoire de Chimie Organique Physique et de Synthèse (LACOPS) BP 526 Cotonou, Bénin
}

(Received September 22, 2008; revised January 22, 2009)

ABSTRACT. This study was aimed to determine the sites of protonation of the molecule during the hydrochlorination of 3-amino-2H-1,2,4-triazole. The catalytic reaction was carried out on the site $\mathrm{MoS}_{3} \mathrm{H}_{3}{ }^{+}$and on the site $\mathrm{ZnCl}_{2}$. On both catalysts, the reaction led to a selective protonation of the molecule on the same atom of nitrogen of the cycle. But the reaction is endothermic and exothermic on the $\mathrm{MoS}_{3} \mathrm{H}_{3}{ }^{+}$and $\mathrm{ZnCl}_{2}$ catalytic sites, respectively. The calculation method used is Hartree-Fock (HF) in the lanl2dz basis set.

KEY WORDS: Catalytic hydrochlorination, 3-Amino-2H-1,2,4-triazole, Protonation, $\mathrm{MoS}_{3} \mathrm{H}_{3}{ }^{+}, \mathrm{ZnCl}_{2}$, Endothermic, Exothermic

\section{INTRODUCTION}

The 3-amino-2H-1,2,4-triazole is a C-amino-1,2,4-triazole called amitrol which is a weed-killer used in agriculture [1,3]. The protonation could improve the properties of this compound by increasing the ease of penetration [4]. So electrochemical studies ended in its use as inhibitor of corrosion [5-6].

In this study we were interested in the simulation of the hydrochlorination of the 3-amino2H-1,2,4-triazole, an experimental study of which was already been reported [4]. The reaction without catalyst was made with the aim of determining the site of protonation of the compound. The catalytic sites used for this reaction are $\mathrm{MoS}_{3} \mathrm{H}_{3}{ }^{+}$and $\mathrm{ZnCl}_{2}$ based upon molybdenum disulfide and zinc chloride, respectively, for the study of the role of the catalyst in this type of reaction.

\section{METHODOLOGY}

Theory

The method used for the calculations is Hartree-Fock (HF) method, an ab initio SCF calculation. This method yields fairly good predictions of bond distances and quite good predictions of bond angles and bond lengths accuracy with a large basis set, at regards the molecular geometry. Dihedral angles are usually calculated reasonably accurately by ab initio SCF MO methods, but number of comparisons with experiment is small. However the data are better in MP2 but require more calculation time. Concerning energy changes, the ab initio SCF MO calculation is used to estimate, for certain type of reactions, the reaction energy. In this method, the wave function is the function of spin-orbitals [7-12]. The electronic energy of the ground state is obtained by applying the variation theorem. In the Hartree-Fock theory, the energy has the form:

$$
E_{H F}=V+\langle h P\rangle+1 / 2\langle P J(P)\rangle-1 / 2\langle P K(P)\rangle
$$

where $\mathrm{V}$ is the nuclear repulsion energy, $\mathrm{P}$ is the density matrix, $(h P)$ is the one-electron (kinetic plus potential) energy, $1 / 2[P J(P)]$ is the classical coulomb repulsion of the electrons and $-1 / 2[P J(P)]$ is the exchange energy resulting from quantum (fermion) nature of electrons.

*Corresponding author. E-mail: menfolben@yahoo.fr; Tel.: (+229) 979805 14/ 90054036 
The basis set used is Lanl2dz. This basis set takes effective core potential (ECP) into account. In fact, core electrons are modeled by a suitable potential function, and only the valence electrons are treated explicitly. Besides double zeta (DZ) yields a better description of the charge distribution compared to a minimal basis. This basis set is less successful than correlation consistent (cc) basis sets [13-16].

Programs of calculation and drawing

The calculations were made with the program Gaussian-98W [17]. The data of the program are the geometry, the multiplicity and the charge of the system. The curves were drawn with Microsoft Office Excel 2003 and the drawings of the studied chemical system were collectively realized with ChemDraw Ultra 6.0, Chem3D Ultra 6.0 and Chemcraft. The work were realized in the "Laboratoire de Chimie Théorique et de Spectroscopie Moléculairé" (LACTHESMO) of the University of Abomey-Calavi in Benin on a computer PH Prntinum 4.

Geometry of the molecule

The geometry of the molecule of triazole is shown in Figure 1 and the geometrical data are given in Table 1.

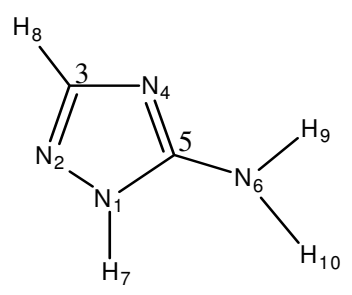

Figure 1. 3-Amino-2H-1,2,4-triazole.

The geometry of $\mathrm{C}_{1}$ symmetry of 3-amino-2H-1,2,4-triazole calculated by HF/Lanl2dz method and that obtained by MP2/TZVP method in the $\mathrm{C}_{\mathrm{s}}$ symmetry of the same molecule [18] are presented in Table 1 .

The values of dihedral angles obtained for atoms forming the cycle (Table 1) confirm that the cycle is planar. The atoms of carbon $\mathrm{C}_{3}$ and $\mathrm{C}_{5}$ are $\mathrm{sp}^{2}$ hybridized and the expected angles have to be of the order of $120^{\circ}$. We noticed that the calculated values vary from $122^{\circ}$ to $126^{\circ}$ for the angles outside the cycle. It is the case of angles $\mathrm{N}_{2} \mathrm{C}_{3} \mathrm{H}_{8}, \mathrm{~N}_{4} \mathrm{C}_{3} \mathrm{H}_{8}, \mathrm{~N}_{4} \mathrm{C}_{5} \mathrm{~N}_{6}$, and $\mathrm{N}_{1} \mathrm{C}_{5} \mathrm{~N}_{6}$. But in the cycle, angles decreased because of the presence of three atoms of nitrogen. It is the case of the angle $\mathrm{N}_{2} \mathrm{C}_{3} \mathrm{H}_{4}$ that is $114.52^{\circ}$ and of the angle $\mathrm{N}_{1} \mathrm{C}_{5} \mathrm{~N}_{4}\left(109.39^{\circ}\right)$ which is more reduced. The atom of nitrogen $\mathrm{N}_{6}$ is $\mathrm{sp}^{3}$ hybridized, the value expected from the angle is $108^{\circ}$ and we noticed that the results are more close to the expected values. The values of dihedrals $\mathrm{N}_{6} \mathrm{C}_{3} \mathrm{~N}_{2} \mathrm{~N}_{1}$ and $\mathrm{H}_{8} \mathrm{C}_{5} \mathrm{~N}_{1} \mathrm{H}_{7}$ showed on the one hand that the atom of nitrogen $\mathrm{N}_{6}$ is in the same plane of the cycle and on the other hand the atoms of hydrogen $\mathrm{H}_{7}$ and $\mathrm{H}_{8}$ are in the same plane. The analysis of the distances allowed to notice that in the cycle the length $\mathrm{C}=\mathrm{N}$ is shorter than the length C-N (Figure 1); but the observed distance is small, which can be explained by the partial aromaticity of the cycle. Thus the length of $\mathrm{N}-\mathrm{N}$ bond is slightly reduced with regard to that given in the literature which is $1.64 \AA$ [19]. 
Table 1. Geometrical data of 3-amino-2H-1,2,4-triazole.

\begin{tabular}{|c|c|c|c|c|c|c|c|c|}
\hline \multicolumn{3}{|c|}{ Bond length $(\AA)$} & \multicolumn{3}{|c|}{ Bond angle $\left({ }^{\circ}\right)$} & \multicolumn{3}{|c|}{ Dihedral angle $\left({ }^{\circ}\right)$} \\
\hline & \multirow{2}{*}{$\begin{array}{c}\mathrm{HF} \\
\text { Lanl2dz }\end{array}$} & \multirow{2}{*}{\begin{tabular}{|c|} 
MP2 \\
TZVP [18]
\end{tabular}} & & \multirow{2}{*}{$\begin{array}{c}\text { HF } \\
\text { Lanl2dz }\end{array}$} & \multirow{2}{*}{\begin{tabular}{|c|} 
MP2 \\
TZVP [18]
\end{tabular}} & \multirow{2}{*}{\multicolumn{2}{|c|}{$\frac{\mathrm{HF}}{\mathrm{Lanl} 2 \mathrm{dz}}$}} & \multirow{2}{*}{\begin{tabular}{|c|} 
MP2 \\
TZVP [18]
\end{tabular}} \\
\hline & & & & & & & & \\
\hline $\mathrm{N}_{1} \mathrm{~N}_{2}$ & 1.392 & 1.357 & $\mathrm{~N}_{2} \mathrm{~N}_{1} \mathrm{C}_{5}$ & 109.59 & 110.57 & $\mathrm{C}_{5} \mathrm{~N}_{1} \mathrm{~N}_{2} \mathrm{C}_{3}$ & -0.005 & - \\
\hline $\mathrm{N}_{1} \mathrm{C}_{5}$ & 1.352 & 1.352 & $\mathrm{~N}_{2} \mathrm{~N}_{1} \mathrm{H}_{7}$ & 120.01 & 119.83 & $\mathrm{~N}_{1} \mathrm{~N}_{2} \mathrm{C}_{3} \mathrm{~N}_{4}$ & 0.008 & - \\
\hline $\mathrm{N}_{2} \mathrm{C}_{3}$ & 1.310 & 1.328 & $\mathrm{C}_{5} \mathrm{~N}_{1} \mathrm{H}_{7}$ & 130.40 & - & $\mathrm{N}_{2} \mathrm{C}_{3} \mathrm{~N}_{4} \mathrm{C}_{5}$ & -0.008 & - \\
\hline $\mathrm{C}_{3} \mathrm{~N}_{4}$ & 1.376 & 1.364 & $\mathrm{~N}_{1} \mathrm{~N}_{2} \mathrm{C}_{3}$ & 102.49 & 101.40 & $\mathrm{C}_{3} \mathrm{~N}_{4} \mathrm{C}_{5} \mathrm{~N}_{1}$ & 0.004 & - \\
\hline $\mathrm{N}_{4} \mathrm{C}_{5}$ & 1.325 & 1.322 & $\mathrm{~N}_{2} \mathrm{C}_{3} \mathrm{~N}_{4}$ & 114.52 & 115.62 & $\mathrm{~N}_{2} \mathrm{~N}_{1} \mathrm{C}_{5} \mathrm{~N}_{6}$ & -179.97 & - \\
\hline $\mathrm{C}_{5} \mathrm{~N}_{6}$ & 1.359 & 1.386 & $\mathrm{~N}_{2} \mathrm{C}_{3} \mathrm{H}_{8}$ & 122.42 & 121.36 & & & \\
\hline $\mathrm{N}_{1} \mathrm{H}_{7}$ & 0.990 & 1.005 & $\mathrm{~N}_{4} \mathrm{C}_{3} \mathrm{H}_{8}$ & 123.06 & - & & & \\
\hline $\mathrm{C}_{3} \mathrm{H}_{8}$ & 1.063 & - & $\mathrm{C}_{3} \mathrm{~N}_{4} \mathrm{C}_{5}$ & 104.01 & 102.57 & & & \\
\hline $\mathrm{N}_{6} \mathrm{H}_{9}$ & 0.992 & - & $\mathrm{N}_{1} \mathrm{C}_{5} \mathrm{~N}_{4}$ & 109.39 & 109.88 & & & \\
\hline \multirow[t]{5}{*}{$\mathrm{N}_{6} \mathrm{H}_{10}$} & 0.991 & - & $\mathrm{N}_{4} \mathrm{C}_{5} \mathrm{~N}_{6}$ & 125.55 & 127.00 & & & \\
\hline & & & N1C5N6 & 125.06 & - & & & \\
\hline & & & $\mathrm{C} 5 \mathrm{~N} 6 \mathrm{H} 9$ & 117.88 & - & & & \\
\hline & & & $\mathrm{C} 5 \mathrm{~N} 6 \mathrm{H} 10$ & 122.56 & - & & & \\
\hline & & & H9N6H10 & 119.56 & 111.05 & & & \\
\hline & & \multicolumn{2}{|c|}{$\mathrm{HF} / \mathrm{Lanl} 2 \mathrm{dz}$} & \multicolumn{2}{|c|}{ MP2/TZVP } & & & \\
\hline \multicolumn{2}{|c|}{ Energy (HF) } & \multicolumn{2}{|c|}{-295.7376} & \multicolumn{2}{|c|}{-297.0045} & & & \\
\hline
\end{tabular}

The adsorption of the 3-amino-2H-1,2,4-triazole on the $\mathrm{MoS}_{3} \mathrm{H}_{3}{ }^{+}$did not cause a big change in the original geometry. There is an angle of deviation from 1 to 2 degrees. Concerning the bond length, there is an elongation of $3.82 \%$ of the $\mathrm{N}_{2} \mathrm{C}_{3}$ bond and a shortening of $4.36 \%$ of the $\mathrm{C}_{3} \mathrm{~N}_{4}$ bond.

In the adsorptive optimized geometry the distance between the atom of Mo and the atom of nitrogen $\mathrm{N}_{2}$ is $2.029 \AA$. This value is close to the length of Mo-N bond [19-22].

As the adsorption on the $\mathrm{ZnCl}_{2}$ is concerned, we noted the elongation of bond $\mathrm{N}_{2} \mathrm{C}_{3}$ of $1 \%$ and the shortening of $2 \%$ of the $\mathrm{C}_{3} \mathrm{~N}_{4}$ bond. In the adsorptive optimized geometry the distance $\mathrm{Zn}-\mathrm{N}_{2}$ is $2.046 \AA$. This value is close to that of the bond $\mathrm{Zn}-\mathrm{N}$ in tetrahedric complexation tris(2-pyridylethylamine zinc(II), in which the values are between 1.979 and $2.028 \AA$ [23].

\section{The process modelling}

The process of hydrochlorination begins from the geometry optimization of the catalystmolecule complex (Figure 2 and 3). The reaction coordinate is the distance between the atom of hydrogen of $\mathrm{HCl}$ and the atom belonging to the cycle of the triazole. When the minimal energy is obtained, we proceed to the desorption by increasing the parameter controlled in the adsorption. 


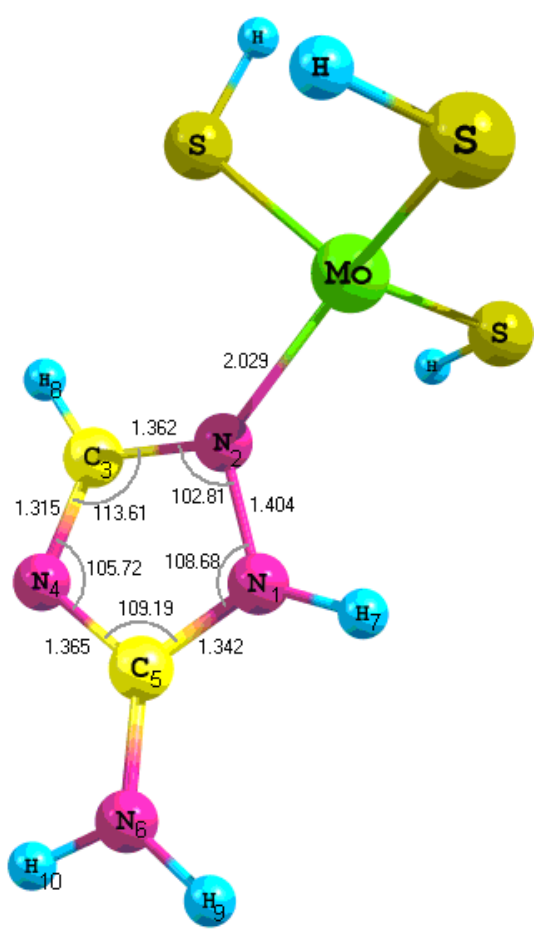

Figure 2. Adsorptive optimized geometry of triazole- $\mathrm{MoS}_{3} \mathrm{H}_{3}{ }^{+}$complex.

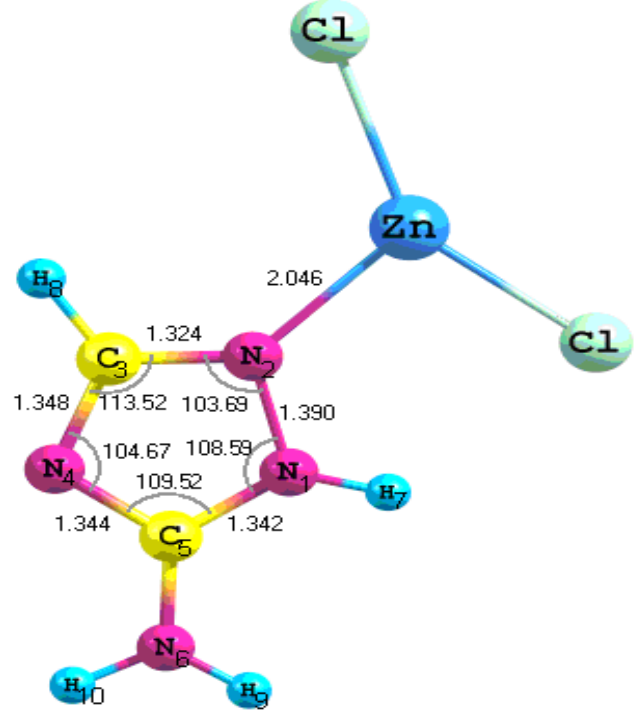

Figure 3. Adsorptive optimized geometry of triazole- $\mathrm{ZnCl}_{2}$ complex.

Bull. Chem. Soc. Ethiop. 2009, 23(2) 


\section{RESULTS AND DISCUSSION}

The hydrochlorination was made without catalyst then with $\mathrm{MoS}_{3} \mathrm{H}_{3}{ }^{+}$and $\mathrm{ZnCl}_{2}$ catalytic sites.

\section{Hydrochlorination without catalyst}

The 3-amino-2H-1,2,4-triazole molecule contains four atoms of nitrogen. The free electron pair of one of them participates in the flavouring of the cycle, it is most likely to be the atom $\mathrm{N}_{1}$. Then, there are three likely sites of protonation. These sites are atoms $\mathrm{N}_{2}, \mathrm{~N}_{4}$ and $\mathrm{N}_{6}$. Then the hydrochlorination was made by approaching one by one these sites by the molecule of hydrogen chloride. Furthermore, we made another symmetric approach so that the atom of hydrogen is almost equidistant between three atoms of nitrogen $\mathrm{N}_{2}, \mathrm{~N}_{4}$ and $\mathrm{N}_{6}$. The various approaches are shown in Figures 4-7.

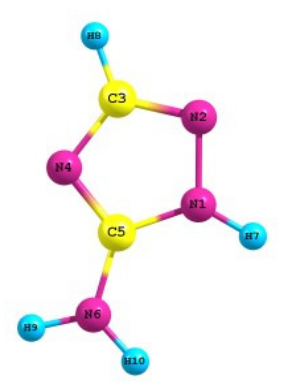

Figure 4. Approach of $\mathrm{HCl}$ on $\mathrm{N}_{2}$ atom.

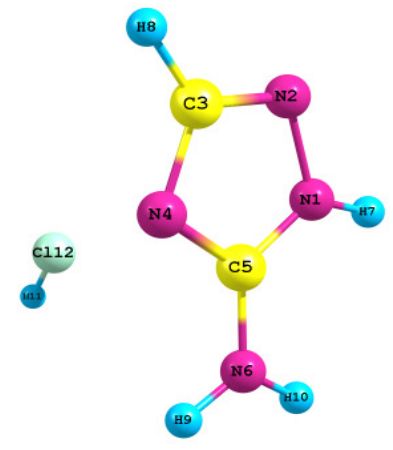

Figure 6. Approach of $\mathrm{HCl}$ on $\mathrm{N}_{6}$ atom.
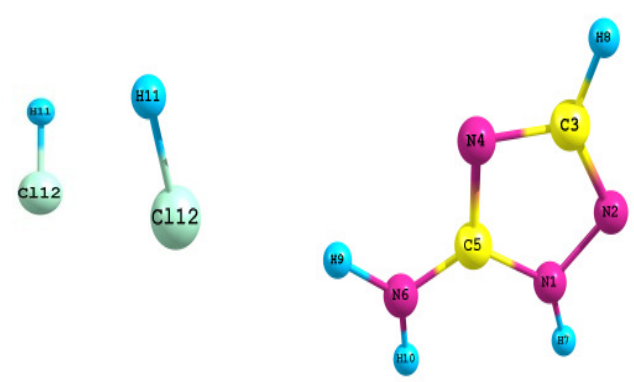

Figure 5. Approach of $\mathrm{HCl}$ on $\mathrm{N}_{4}$ atom.

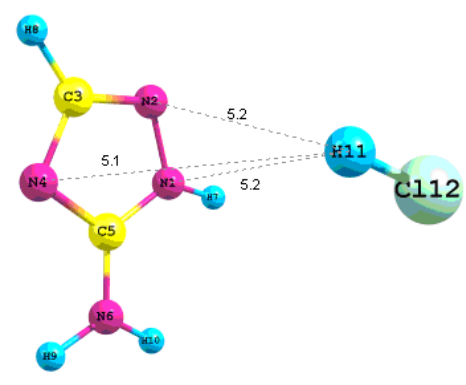

Figure 7. Symmetrical approach of $\mathrm{HCl}$ with regard to the triazolic ring.

\section{Approach of $\mathrm{HCl}$ on $\mathrm{N}_{2}$ atom}

The atom of hydrogen $\left(\mathrm{H}_{11}\right)$ of $\mathrm{HCl}$ is approached the atom of nitrogen $\mathrm{N}_{2}$ of the triazole. The curve of the variation of the energy of the system according to the distance $\mathrm{H}_{11}-\mathrm{N}_{2}$ is represented (Figure 8). This graphical representation indicates the stability of the final system with regard to the initial system by the fact of a lower energy at the end of the reaction.

Bull. Chem. Soc. Ethiop. 2009, 23(2) 


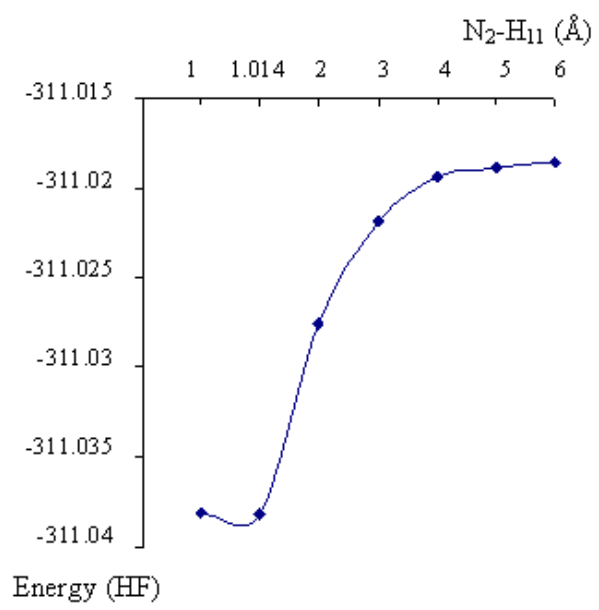

Figure 8. Hydrochlorination of 3-amino-2H-1,2,4-triazole during approach $\mathrm{N}_{2}$ without catalyst.

During the approach, we noted a progressive stretching of $\mathrm{H}_{11}-\mathrm{Cl}_{12}$ bond and at the end we observed the break of this last one. The $\mathrm{H}_{11}$ atom is then fixed itself to the atom of nitrogen $\mathrm{N}_{2}$ at a distance of $1.014 \AA$, value close to that of the bond N-H in the literature (1.01 $\AA$ ) [19]. We obtained as product, the chlorhydrate of 3-amino- $2 \mathrm{H}-1,2,4$ triazolium protoned on $\mathrm{N}_{2}$. However, the atom of chlorine established no bond with another atom. Then we have formation of a salt. The values of the charges of atoms (Table 2) allow us to confirm it.

Table 2. Atomic charges of Mulliken during the approach.

\begin{tabular}{|c|c|c|c|c|}
\hline \multirow{2}{*}{ Atoms } & \multicolumn{4}{|c|}{ Charges (au) } \\
\cline { 2 - 5 } & \multirow{2}{*}{ Start of reaction } & \multicolumn{3}{|c|}{ End of reaction } \\
\cline { 2 - 5 } & & Approach $\mathrm{N}_{2}$ & Approach $\mathrm{N}_{4}$ & Approach $_{6}$ \\
\hline N1 & -0.557 & -0.417 & -0.545 & -0.417 \\
\hline N2 & -0.109 & -0.310 & -0.048 & -0.310 \\
\hline C3 & -0.088 & 0.065 & 0.030 & 0.065 \\
\hline N4 & -0.331 & -0.305 & -0.559 & -0.305 \\
\hline C5 & 0.481 & 0.540 & 0.653 & 0.540 \\
\hline N6 & -0.802 & -0.783 & -0.762 & -0.783 \\
\hline H7 & 0.401 & 0.440 & 0.435 & 0.440 \\
\hline H8 & 0.242 & 0.281 & 0.285 & 0.281 \\
\hline H9 & 0.396 & 0.414 & 0.437 & 0.414 \\
\hline H10 & 0.367 & 0.402 & 0.387 & 0.401 \\
\hline H11 & 0.223 & 0.457 & 0.437 & 0.457 \\
\hline C112 & -0.223 & -0.784 & -0.749 & -0.784 \\
\hline
\end{tabular}

The charge of Mulliken of the atom of chlorine which was -0.223 u.a. in the molecule of $\mathrm{HCl}$ is crossed in -0.784 u.a., we noticed that the negative charge strongly increased. And the atom of nitrogen $\mathrm{N}_{2}$ which was bound in the hydrogen $\mathrm{H}_{11}$ also increased its negative charge which passes of -0.109 u.a. in -0.310 u.a. while that of the atom $\mathrm{N}_{4}$ varies little (Table 2). All the cycle of the triazole is positively charged with and the positive poles are the atoms of carbon and hydrogen; all the atoms of nitrogen were negatively charged. We noted that the atom of carbon $\mathrm{C}_{3}$ which was negatively charged at the beginning of the reaction possesses a positive charge at 
the end. Nevertheless, the atom $\mathrm{C}_{5}$ is more positive. The Cartesian coordinates of the salt introduced into the software Chemcraft allowed to have the spatial representation of the chemical system at the end of the process (Figure 9).
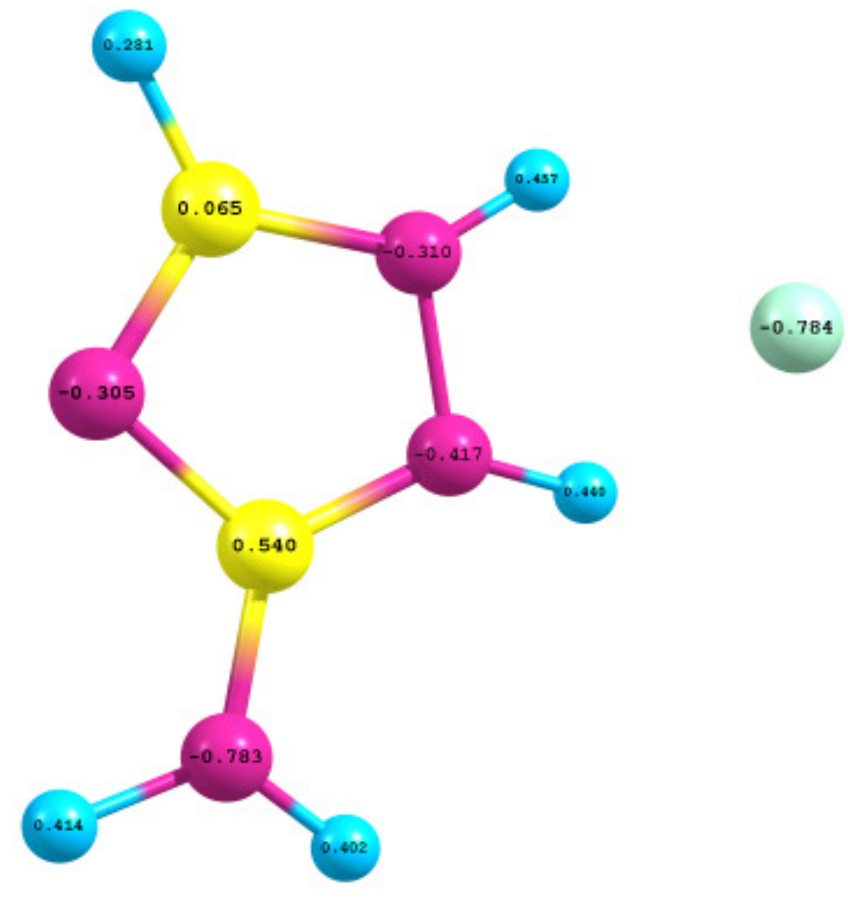

Figure 9. Reaction product during approach $\mathrm{N}_{2}$

The dipole moment of the reaction product is $9.813 \mathrm{D}$, which explains the presence of a dipole. We noticed an increase of dipole moment which was $4.4178 \mathrm{D}$ in the 3-amino-2H-1,2,4triazole.

The energy of the reaction product is -311.03816 u.a. now adds to the energies of the 3amino-2H-1,2,4-triazole and some chloride of hydrogen is -311.0144 u.a. then the reaction is exothermic with an energy $\Delta \mathrm{E}_{2}=-0.0237$ u.a. $\left(-62.303 \mathrm{~kJ} \mathrm{~mol}^{-1}\right)$.

\section{Approach of $\mathrm{HCl}$ on $\mathrm{N}_{4}$ atom}

The atom of hydrogen $\left(\mathrm{H}_{11}\right)$ of $\mathrm{HCl}$ is approached the atom of nitrogen $\mathrm{N}_{4}$ of the triazole. The representative curve of the variation of the energy of the system according to the distance $\mathrm{N}_{4}-\mathrm{H}_{11}$ is given in Figure 10. This graph indicates the stability of the final system with regard to the initial system by the fact of a lower energy at the end of the process.

At the end of the reaction we observed the break of the bond $\mathrm{H}_{11}-\mathrm{Cl}_{12}$ and the formation of bond $\mathrm{N}_{4}-\mathrm{H}_{11}$ with a length of $1.028 \AA$ value close to that of the bond $\mathrm{N}-\mathrm{H}$ in the literature $(1.01$ $\AA$ A) [19]. We obtained a salt the chlorhydrate of 3 -amino- $2 \mathrm{H}-1,2,4$ triazolium protonedon $\mathrm{N}_{4}$ as product of reaction because the atom of chlorine not established any bond. It is verified by the distribution of charge in the product. The chlorine is negatively charged and the cycle is positively charged. The positive poles are the atoms of carbons (Table 2), but with a stronger 
concentration on the atom $\mathrm{C}_{5}$. It could be explained by the fact that the chlorine is closer to $\mathrm{C}_{5}$ than to $\mathrm{C}_{3}$.

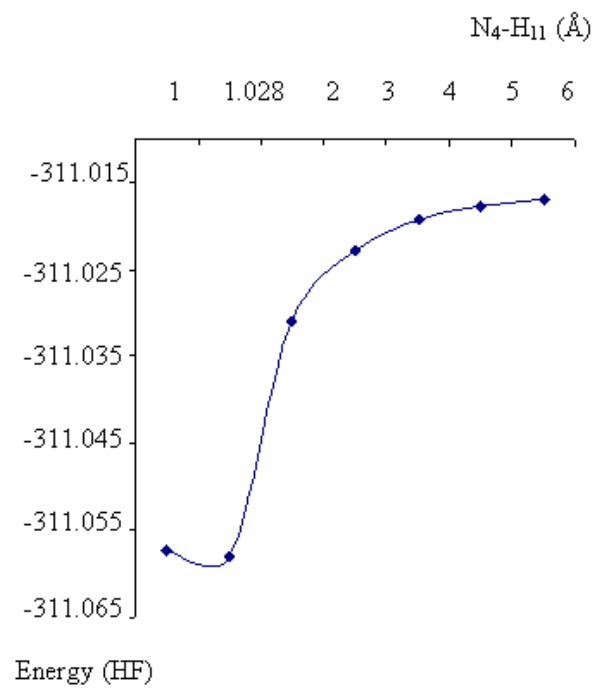

Figure 10. Hydrochlorination of 3-amino-2H-1,2,4-triazole during approach $\mathrm{N}_{4}$ without catalyst.

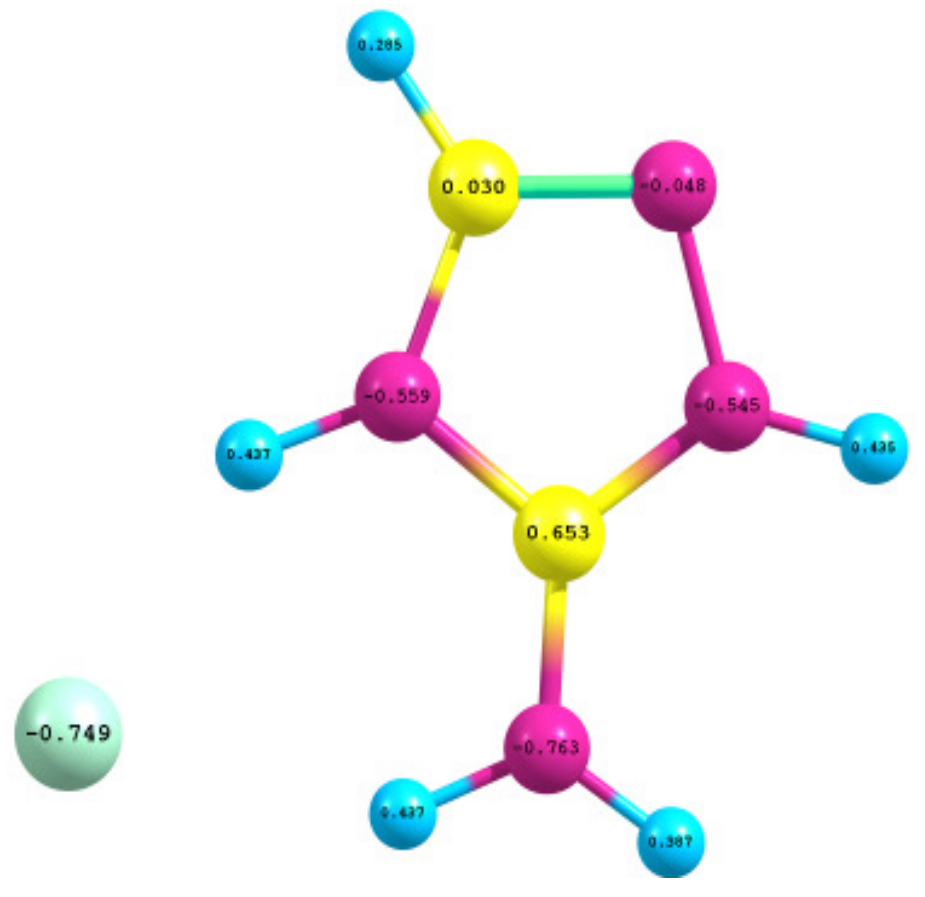

Figure 11. Reaction product during approach $\mathrm{N}_{4}$.

Bull. Chem. Soc. Ethiop. 2009, 23(2) 
We noted in this approach a movement more pronounced by negative charges towards the atom $\mathrm{N}_{4}$. It can be for the presence of the atom $\mathrm{H}_{11}$ on this last one. Indeed the charge of Mulliken of the atom $\mathrm{N}_{4}$ crosses -0.331 u.a. at -0.559 u.a. while that of the atom $\mathrm{N}_{2}$ crosses -0.109 u.a. at -0.048 u.a. The salt formed during the reaction is represented (Figure 11).

The product obtained during the approach $\mathrm{N}_{4}$ have a dipole moment of $9.9358 \mathrm{D}$, value which is superior to that of the 3 -amino-2H-1,2,4-triazole. The energy of the obtained product is -311.0578 u.a. or the energy of initial system is -311.0144 u.a. So the reaction is exothermic with an energy $\Delta \mathrm{E}_{4}=-0.0434$ u.a. $\left(-113.999 \mathrm{~kJ} \cdot \mathrm{mol}^{-1}\right)$.

Approach of $\mathrm{HCl}$ on atom $\mathrm{N}_{6}$

The atom of hydrogen $\left(\mathrm{H}_{11}\right)$ of $\mathrm{HCl}$ is approached the atom of nitrogen $\mathrm{N}_{6}$ of the triazole. The representative curve of the variation of the energy of the system according to the distance $\mathrm{N}_{6}-\mathrm{H}_{11}$ is shown in Figure 12. This curve indicates the stability of the final system with regard to the initial system by the fact of a lower energy at the end.

$$
\mathrm{N}_{6}-\mathrm{H}_{11}(\AA)
$$

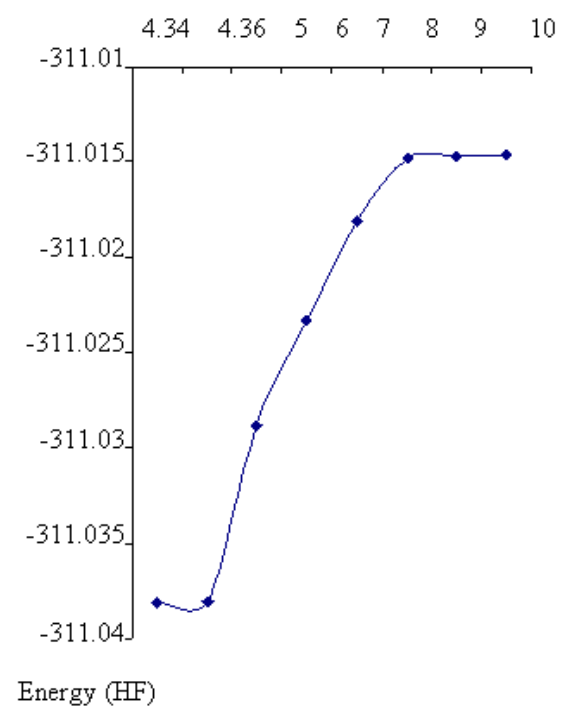

Figure 12. Hydrochlorination of 3-amino-2H-1,2,4-triazole during approach $\mathrm{N}_{6}$ without catalyst.

We observe that the atom of hydrogen of $\mathrm{HCl}$ settles on the atom of nitrogen $\mathrm{N}_{2}$ in a distance of $1.014 \AA$ as in the case of the approach on $\mathrm{N}_{2}$. We obtained as product the chlorhydrate of 3-amino-2H-1,2,4 triazolium protonated on $\mathrm{N}_{2}$. The charges of atoms at the beginning and at the end of reaction are given in Table 2.

We noticed that charges at the end of reaction are equal to the thousandth near to that of the product of the approach on $\mathrm{N}_{2}$. The obtained product is shown in Figure 13.

We noted that the product obtained during the approach on $\mathrm{N}_{6}$ is identical to that of the approach on $\mathrm{N}_{2}$. We observed it by the fact that the various atoms carry identical charges in both and also by the equality of the dipole moment which is of $9.813 \mathrm{D}$. Then it could mean that the protonation of the 3-amino- $2 \mathrm{H}-1,2,4$-triazole cannot be made on the atom $\mathrm{N}_{6}$; what is in compliance with the results of Zaza et al. works on the study vibrationnal of $(1 \mathrm{H})-5$-amino1,2,4-triazol and of its chlorhydrate [4].

Bull. Chem. Soc. Ethiop. 2009, 23(2) 
The energy of the reaction during the approach on $\mathrm{N}_{6}$ is equal to that of the approach on $\mathrm{N}_{2}$, i.e. $\Delta \mathrm{E}_{6}=-0.0237$ u.a. $\left(-62.303 \mathrm{~kJ} \cdot \mathrm{mol}^{-1}\right)$.
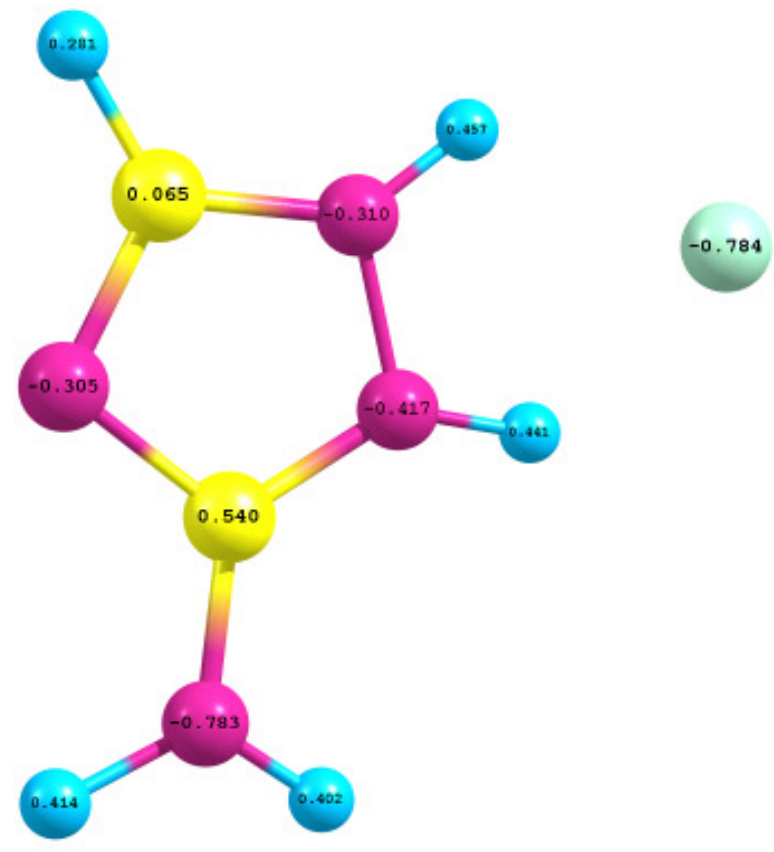

Figure 13. Reaction product during approach $\mathrm{N}_{6}$.

Symmetric approach of $\mathrm{HCl}$ with regard to the triazolique ring

We approached $\mathrm{HCl}$ with a geometry of beginning such as the distances $\mathrm{H}_{11}-\mathrm{N}_{1} ; \mathrm{H}_{11}-\mathrm{N}_{2}$ and $\mathrm{H}_{11}$ $\mathrm{N}_{4}$ is included between $5.1 \AA$ and $5.2 \AA$. The curve of the variation of the energy of the system according to the distance $\mathrm{H}_{11}-\mathrm{N}_{2}$ is represented (Figure 14). The curve shows that the final state is more stable than the initial state. The reaction is thus exothermic.

During this symmetric approach, the atom of hydrogen turned to the atom of nitrogen $\mathrm{N}_{4}$, and the bond $\mathrm{H}_{11}-\mathrm{Cl}_{12}$ lengthened gradually until break. It could be explained by the fact of the steric effect at the level of the atom $\mathrm{N}_{4}$. At the end of the reaction the length of the formed bond $\mathrm{N}_{4}-\mathrm{H}_{11}$ is $1.028 \AA$ value of a bond $\mathrm{N}-\mathrm{H}$. The formed salt is the same that obtained during the approach on the atom $\mathrm{N}_{4}$. What is translated by the same value of dipole moment which is about 9.93 $\mathrm{D}$ and also the values of the charges of atoms (Figure 15).

The energy of reaction of the symmetric approach is equal to that of the approach on the atom $\mathrm{N}_{4}$, i.e. $\Delta \mathrm{E}_{4}=-0.0434$ u.a. $\left(-113.999 \mathrm{~kJ} \cdot \mathrm{mol}^{-1}\right)$.

As a matter of fact, of the three sites of protonation, two sites are most likely to be protonated, that is the sites $\mathrm{N}_{2}$ and $\mathrm{N}_{4}$. But the most stable product is the one of the protonation on the site $\mathrm{N}_{4}$ by comparing the energies of obtained salts. 


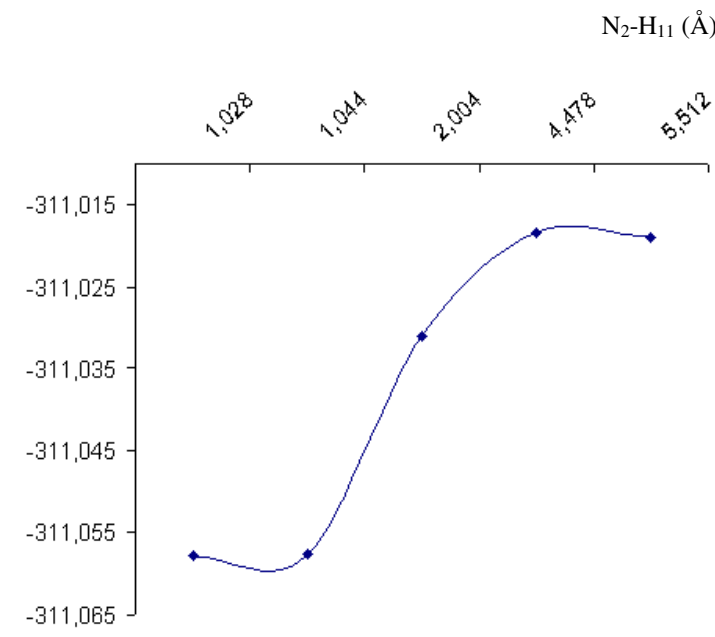

Energy HF

Figure 14. Hydrochlorination of 3-amino-2H-1,2,4-triazole during symmetrical approach without catalyst .

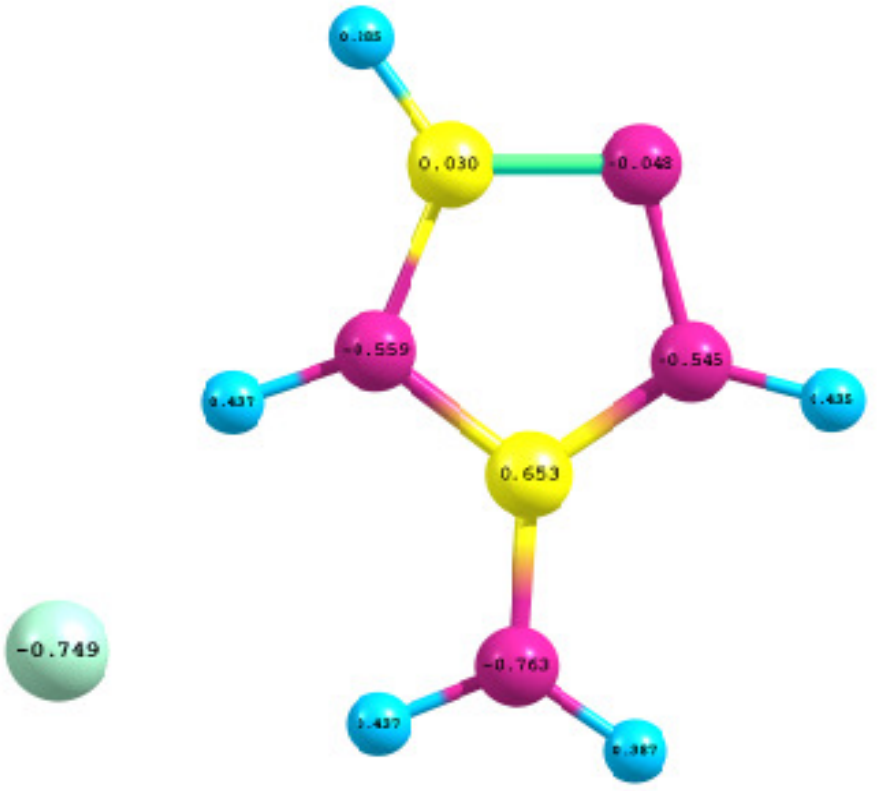

Figure 15. Reaction product during symmetrical approach.

Hydrochlorination of the 3-amino-1,2,4-triazole on $\mathrm{MoS}_{3} \mathrm{H}_{3}^{+}$

We approached the molecule of the chloride of hydrogen on the adsorbed molecule. This approach was made on the atom of nitrogen $\mathrm{N}_{4}$ from the distance $\mathrm{N}_{4}-\mathrm{H}$ equal to $5 \AA$. The

Bull. Chem. Soc. Ethiop. 2009, 23(2) 
representative curve of the variation of the energy of the system according to the distance $\mathrm{N}_{4}-\mathrm{H}$ is given in Figure 16. This energy curve shows a final system less stable than an initial system. The energy of the end of reaction being more raised the reaction would be then endothermic. The curve shows a summit characterized by a state of transition, which is confirmed by one and a single imaginary frequency $\left(660.1 \mathrm{~cm}^{-1}\right)$. In this state of transition the connection $\mathrm{H}-\mathrm{Cl}$ is practically broken and the atom of hydrogen is $1.2 \AA$ of the atom of nitrogen $\mathrm{N}_{4}$.

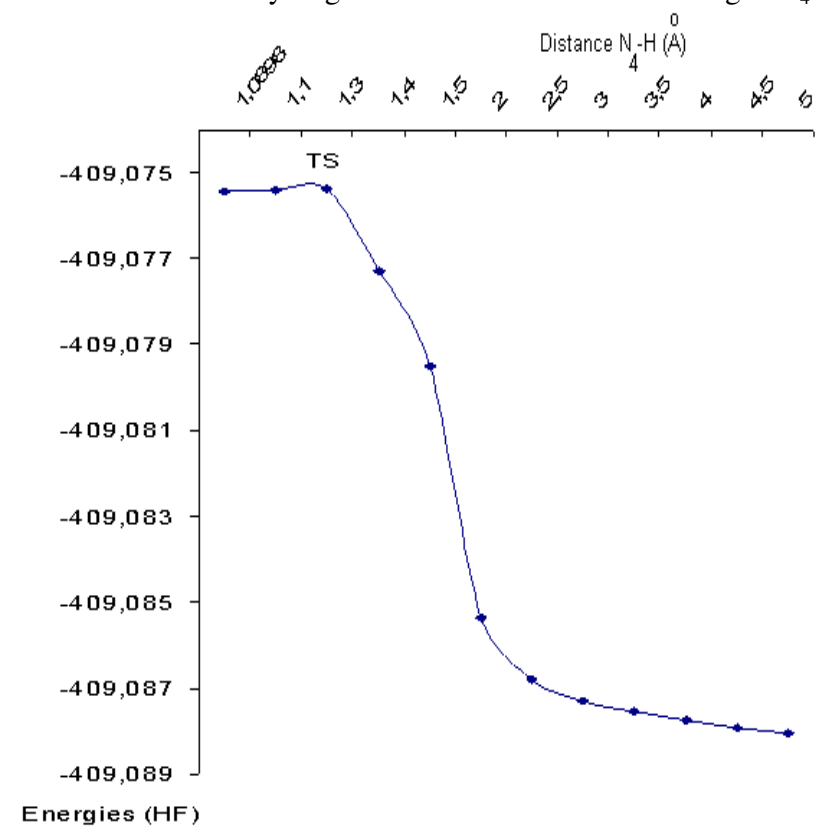

Figure 16. Hydrochlorination of 3-amino-2H-1,2,4-triazole on $\mathrm{MoS}_{3} \mathrm{H}_{3}{ }^{+}$catalytic site.

In the end product is a salt. We observed the formation of the bond $\mathrm{N}_{4}-\mathrm{H}$ with a distance of $1.090 \AA$ A . During the desorption of the product, the distance $\mathrm{N}_{4}-\mathrm{H}$ decreases but the system destabilizes because the energy increases. Indeed for an increase $\Delta=1.4 \AA$ of the distance Mo- $\mathrm{N}_{2}$ the energy of the system passes from -409.0754 u.a. to -409.0100 u.a. The evolution of the system during the reaction is represented (Figure 17).

During the desorption, the length of the bond $\mathrm{N}_{4}-\mathrm{H}$ has deceased by $0.4 \AA$. Then this bond becomes more stronger. At the same time the $\mathrm{C}_{5}-\mathrm{N}_{6}$ bond length increased slightly from $1.304 \AA$ to $1.313 \AA$. The energy of the reaction is given in Table 3 .

Table 3. Hydrochlorination of 3-amino-2H-1,2,4-triazole on $\mathrm{MoS}_{3} \mathrm{H}_{3}{ }^{+}$catalytic site.

\begin{tabular}{|c|c|c|c|c|}
\hline \multicolumn{4}{|c|}{ Energy (au) } & \multirow[b]{2}{*}{$\begin{array}{c}\Delta \mathrm{E} \\
\left(\mathrm{kJ} \cdot \mathrm{mol}^{-1}\right)\end{array}$} \\
\hline $\begin{array}{c}\text { Complex } \\
\mathrm{MoS}_{3} \mathrm{H}_{3}{ }^{+} \text {-3-amino-2H-1,2,4-triazole }\end{array}$ & $\mathrm{HCl}$ & $\mathrm{C}_{2} \mathrm{~N}_{4} \mathrm{H}_{5} \mathrm{Cl}-\mathrm{MoS}_{3} \mathrm{H}_{3}{ }^{+}$ & $\Delta \mathrm{E}$ & \\
\hline-393.8047 & -15.2769 & -409.0754 & 0.0061 & 16.121 \\
\hline
\end{tabular}

$* \Delta \mathrm{E}=$ energy of reaction.

The reaction being endothermic it consumes the heat but without the catalyst the reaction is exothermic thus it is possible that the $\mathrm{MoS}_{3} \mathrm{H}_{3}{ }^{+}$is not a catalyst indicated for this reaction.

Bull. Chem. Soc. Ethiop. 2009, 23(2) 

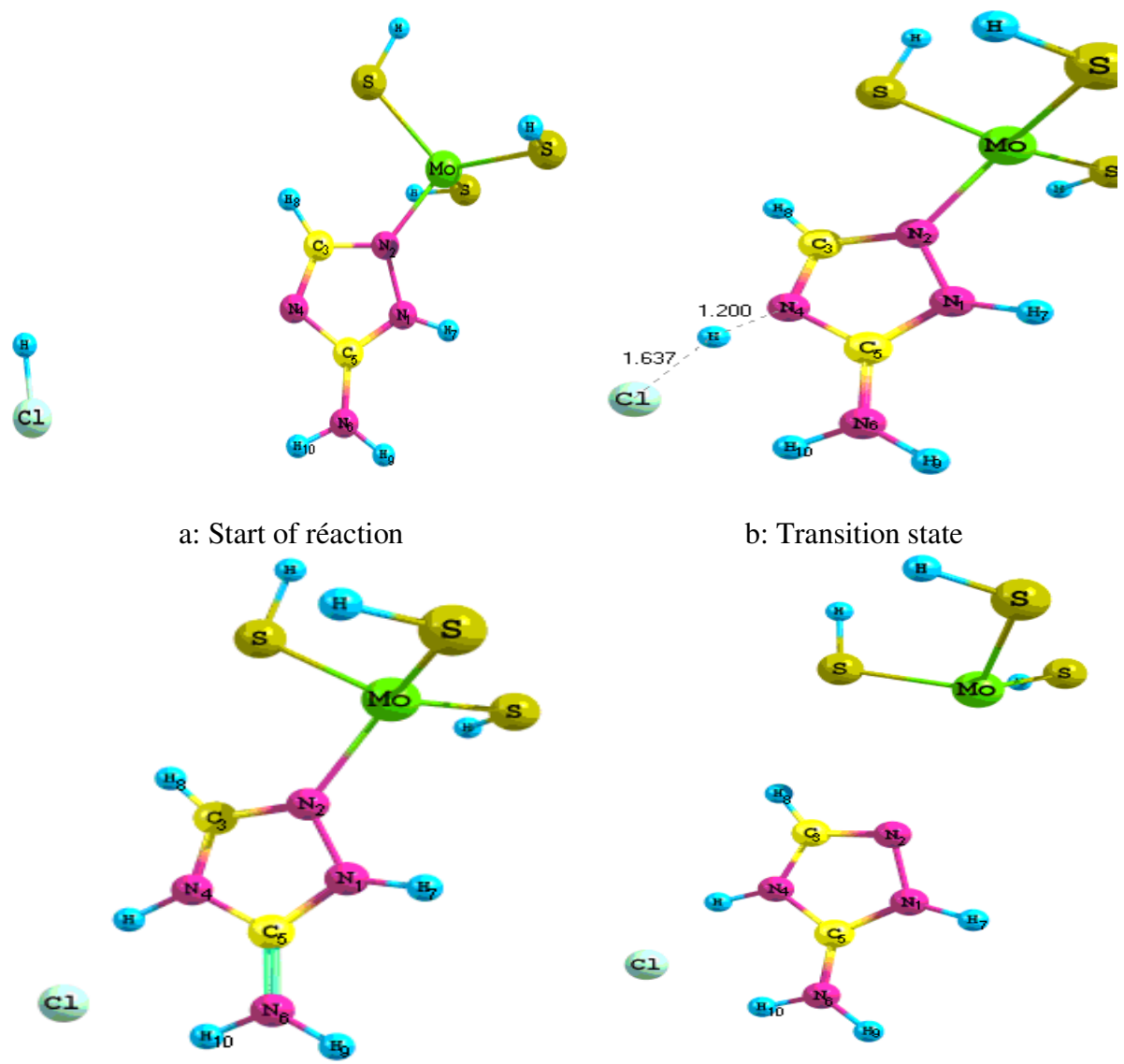

b: Transition state

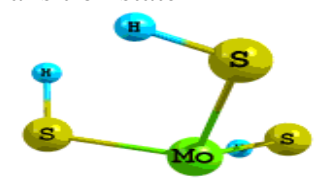

c: End of reaction

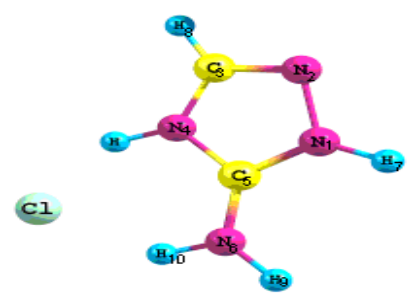

d: Desorption of the product

Figure 17. Geometrical structure of the system during the hydrochlorination of 3 -amino- $2 \mathrm{H}$ 1,2,4-triazole on $\mathrm{MoS}_{3} \mathrm{H}_{3}{ }^{+}$catalytic site.

Hydrochlorination of the 3-amino-2H-1,2,4-triazole on $\mathrm{ZnCl}_{2}$

We approached the molecule of hydrogen chloride of the adsorbed molecule. At first, an approach was made on the atom of nitrogen $\mathrm{N}_{4}$ from the distance $\mathrm{N}_{4}-\mathrm{H}$ equal to $5 \AA$ and another approach was made in equidistant way of the atoms of nitrogen $\mathrm{N}_{1}, \mathrm{~N}_{2}$ and $\mathrm{N}_{4}$.

As for the first approach, the representative curve of the variation of the energy of the system according to the distance $\mathrm{N}_{4}-\mathrm{H}$ is shown in Figure 18. This energy curve shows a final system more stable than an initial system. The energy of the end of reaction being lower the reaction would be then exothermic. 


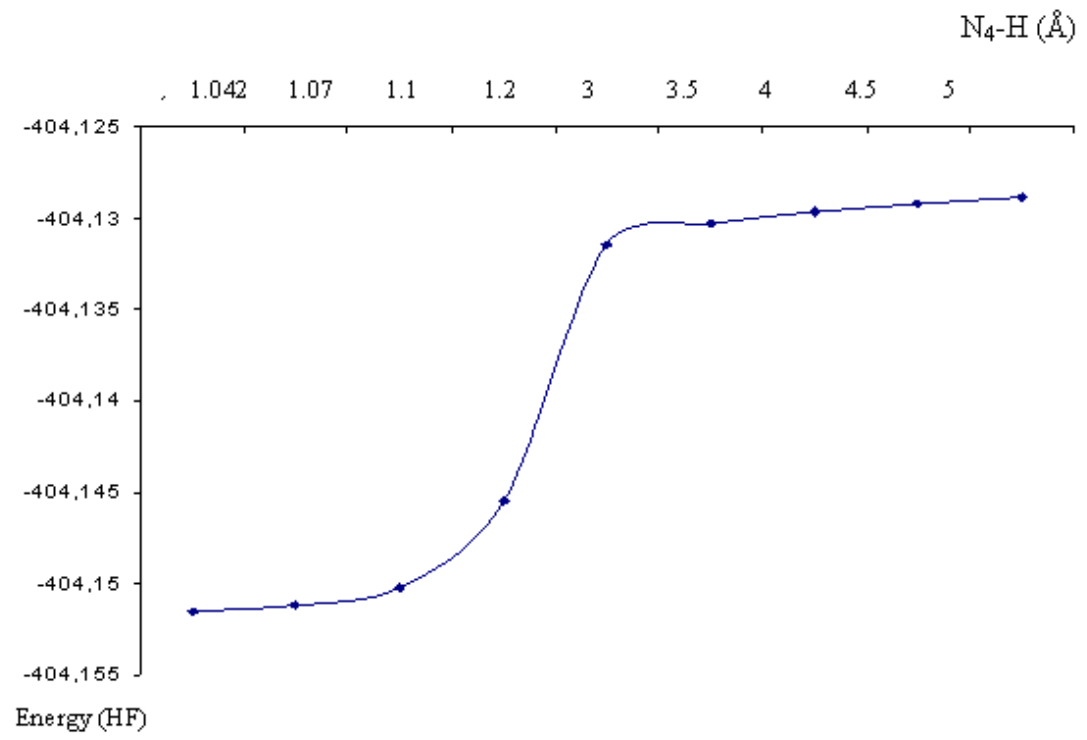

Figure 18. Hydrochlorination of 3-amino-2H-1,2,4-triazole on $\mathrm{ZnCl}_{2}$ during approach $\mathrm{N}_{4}$.

At the end of the reaction there is formation of the bond $\mathrm{N}_{4}-\mathrm{H}$ the length of which is 1.045 $\AA$. When the complex is desorbed this distance passes at $1.027 \AA$; and the $\mathrm{ZnCl}_{2}$ finds its linear structure of beginning and the chlorhydrate of 3-amino- $2 \mathrm{H}-1,2,4$ triazolium protonated on $\mathrm{N}_{4}$ is obtained as product. The evolution of the system during the reaction is represented (Figure 19).

We observed that the salt obtained after the desorption from the site $\mathrm{ZnCl}_{2}$ has the same structure as that obtained during the approach on $\mathrm{N}_{4}$ and on $\mathrm{N}_{6}$. The double bond $\mathrm{C}_{3}=\mathrm{N}_{2}$ is established well with a length of $1.294 \AA$. The length of the bond $\mathrm{N}_{4}-\mathrm{H}$ is $1.027 \AA$ practically equal to that observed during the approach without the catalyst on $\mathrm{N}_{4}$. The distribution of charges (Figure 20) after the desorption is similar to that of the product of the approach on $\mathrm{N}_{4}$ (Figure 11), the total Mulliken charge of $\mathrm{ZnCl}_{2}$ being 0.006 u.a. The energy of the reaction is given in Table 4.

Table 4. Hydrochlorination of 3-amino-2H-1,2,4-triazole on $\mathrm{ZnCl}_{2}$ catalytic site.

\begin{tabular}{|c|c|c|c|c|}
\hline \multicolumn{4}{|c|}{ Energy $(\mathrm{au})$} & \multirow[b]{2}{*}{$\begin{array}{c}\Delta \mathrm{E} \\
\left(\mathrm{kJ} \cdot \mathrm{mol}^{-1}\right)\end{array}$} \\
\hline $\begin{array}{c}\text { Complex } \\
\mathrm{ZnCl}_{2}-3 \text {-amino-2H-1,2,4-triazole }\end{array}$ & $\mathrm{HCl}$ & $\mathrm{C}_{2} \mathrm{~N}_{4} \mathrm{H}_{5} \mathrm{Cl}-\mathrm{ZnCl}_{2}$ & $\Delta \mathrm{E}$ & \\
\hline-388.8505 & -15.2769 & $-404,1516$ & -0.0241 & -63.353 \\
\hline
\end{tabular}

The reaction is exothermic as for the reaction without the catalyst. But the energy of reaction decreases in value absolved with regard to that of the reaction without the catalyst.

As for the symmetric approach of the molecule of $\mathrm{HCl}$ towards three atoms of nitrogen of the ring, the curve of the variation of the energy of the system according to the distance $\mathrm{H}-\mathrm{N}_{4}$ is represented (Figure 21). This curve shows that the reaction is exothermic because the final state is more stable than the initial state. So we observed a state of transition which is obtained with a distance $\mathrm{H}-\mathrm{N}_{4}$ equal to $3.753 \AA$. This state of transition is characterized well by the presence of one and a single imaginary frequency of $68.89 \mathrm{~cm}^{-1}$.

Bull. Chem. Soc. Ethiop. 2009, 23(2) 

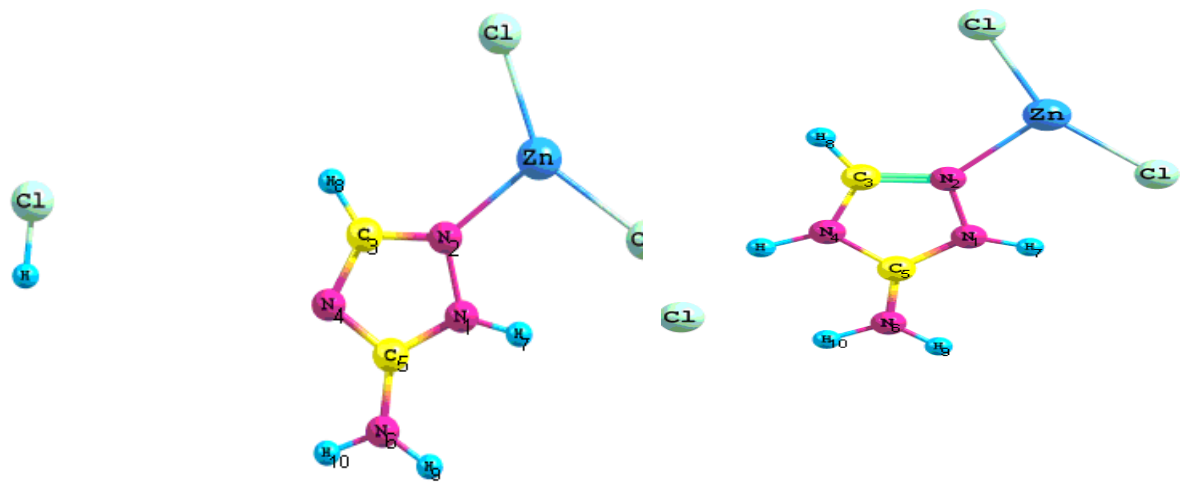

a: Start of reaction

b: End of reaction
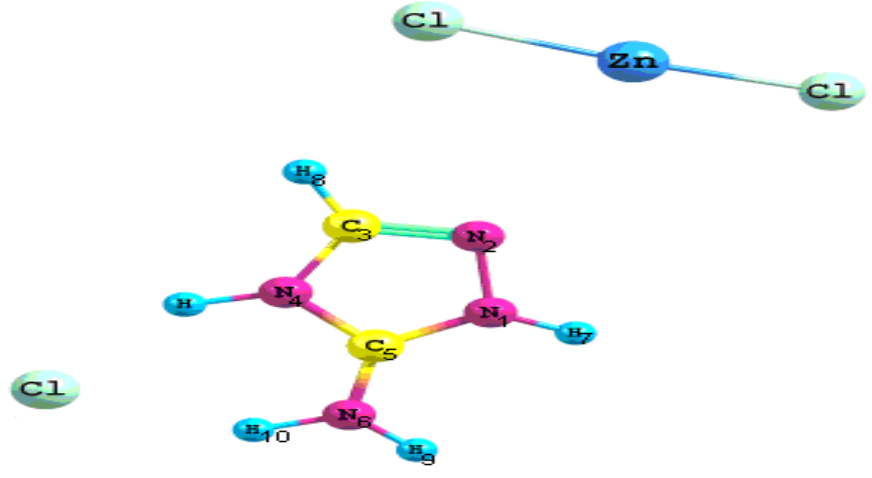

c: Desorption of the product

Figure 19. Geometrical structure of the system during the hydrochlorination of 3-amino-2H1,2,4-triazole on $\mathrm{ZnCl}_{2}$ catalytic site during approach $\mathrm{N}_{4}$

In this state of transition we noticed that the atom of hydrogen approached closer to atoms $\mathrm{N}_{1}$ and $\mathrm{N}_{2}$ of more than the bond between the atom of hydrogen and the atom of chlorine of the $\mathrm{HCl}$ which is slightly stretched in passing of $1.289 \AA$ to $1.291 \AA$ (Figure 22). The different phases of the process are represented in Figure 22.

We observed that the brought hydrogen settled on the atom $\mathrm{N}_{4}$ during the symmetric approach with $1.04 \AA$ as length. The product obtained during the symmetric approach is the same as that obtained during the approach on the atom $\mathrm{N}_{4}$. Then the energy of reaction is same, $\Delta \mathrm{E}=-63.353 \mathrm{~kJ} \cdot \mathrm{mol}^{-1}$.

The presence of the catalyst entailed only the protonation on the atom of nitrogen $\mathrm{N}_{4}$ following all the examined approaches. It can be explained by a steric effect around the atom $\mathrm{N}_{2}$ due to the presence of the $\mathrm{ZnCl}_{2}$. While during the reaction without the catalyst led to the protonation on atoms $\mathrm{N}_{2}$ and $\mathrm{N}_{4}$ according to the various approaches, the symmetric approach entails the protonation of the atom $\mathrm{N}_{2}$. Thus the zinc chloride acts as guidance in this reaction. 

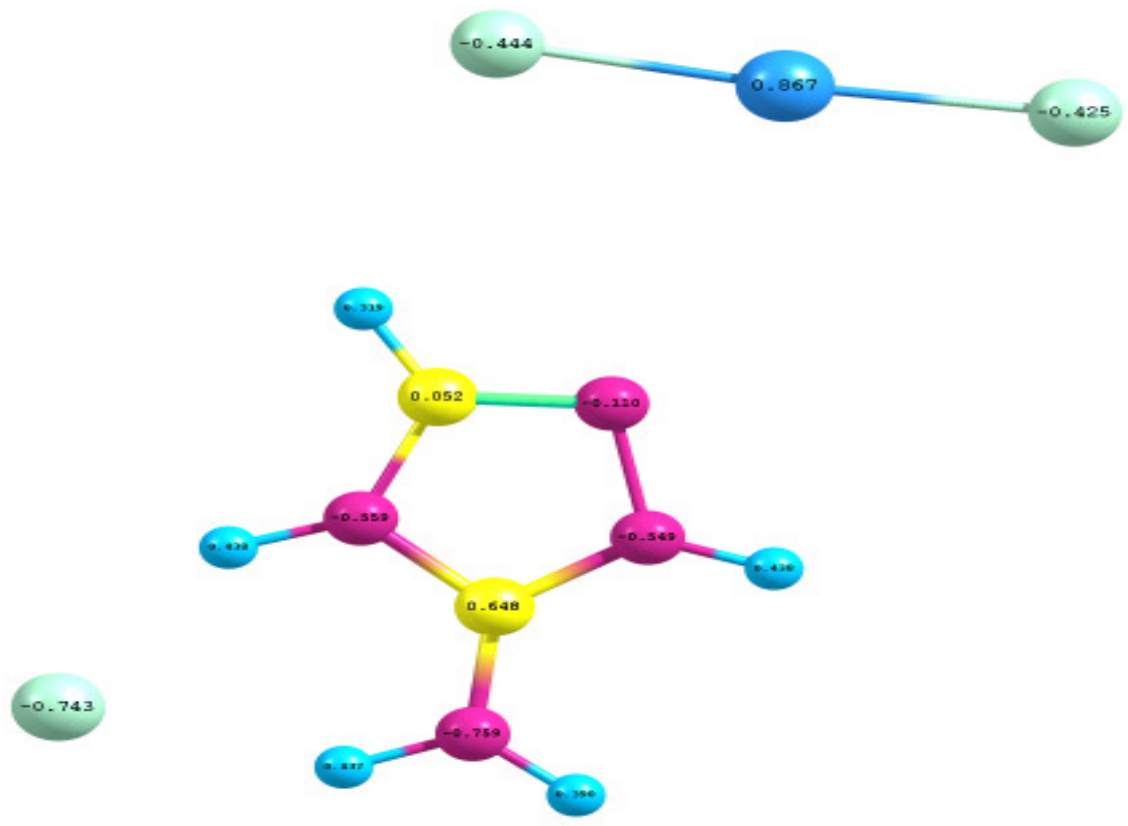

Figure 20. Distribution of charges after desorption of the reaction product.

$$
\mathrm{N}_{4}-\mathrm{H}(\mathrm{A})
$$

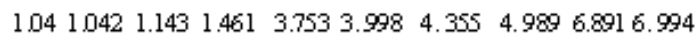

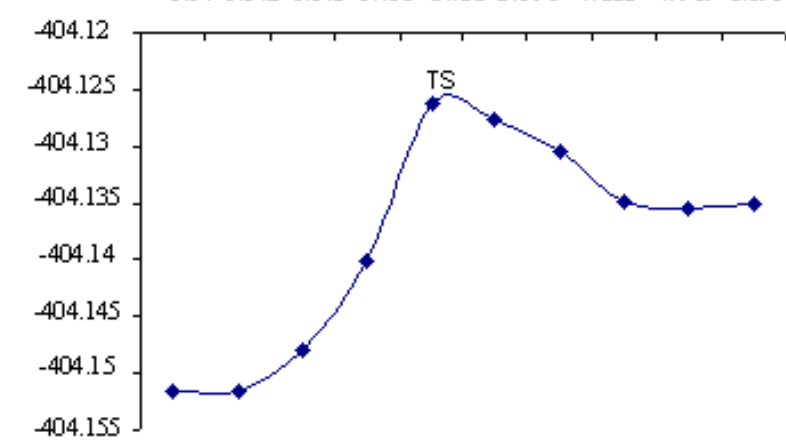

Energy (HF)

Figure 21. Hydrochlorination of 3-amino-2H-1,2,4-triazole on $\mathrm{ZnCl}_{2}$ during symmetrical approach. 

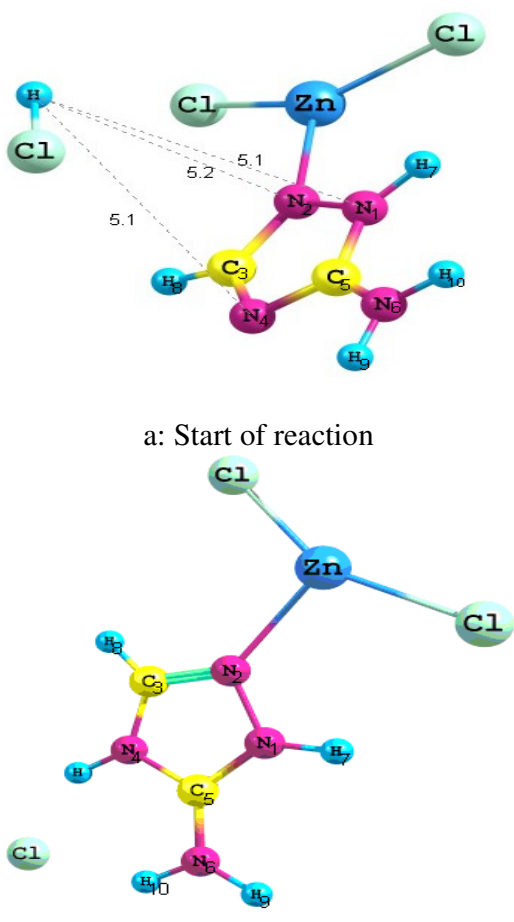

c: End of reaction

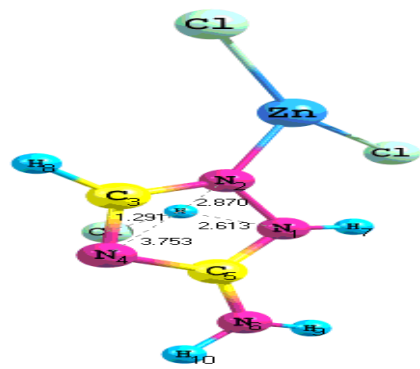

b: Transition state
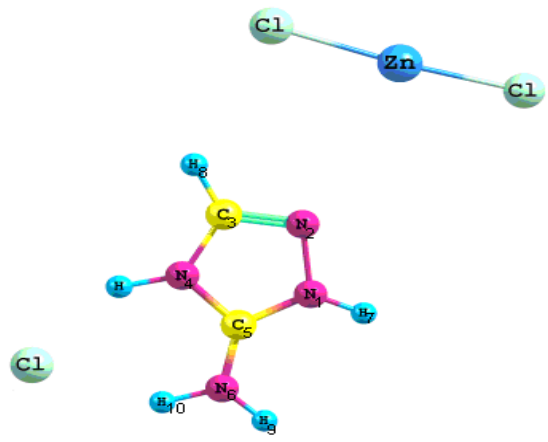

d: Desorption of the product

Figure 22. Geometrical structure of the system during the hydrochlorination of 3 -amino-2H1,2,4-triazole on the site $\mathrm{ZnCl}_{2}$ during symmetrical approach.

\section{CONCLUSIONS}

In this work, the ability of the 3-amino-2H-1,2,4-triazole to react with $\mathrm{HCl}$ was approached by modelling its hydrochlorination. This hydrochlorination was made without the catalyst then on two catalytic sites $\mathrm{MoS}_{3} \mathrm{H}_{3}{ }^{+}$and $\mathrm{ZnCl}_{2}$. The results showed according to previous works found in the literature that the amine group is not protonated during the hydrochlorination, but rather both atoms of nitrogen of the ring among which the one gives a more stable product. So the catalytic site $\mathrm{MoS}_{3} \mathrm{H}_{3}{ }^{+}$is not favorable to this reaction. As for the site $\mathrm{ZnCl}_{2}$, its role seems to limit itself essentially to the facilitation of the protonation of one of the atoms of nitrogen of the cycle.

Finally, the validation of our model will depend on results obtained experimentally on the molecule in the same conditions.

\section{REFERENCES}

1. Inoue, Y.; Ogawa, T.; Shibata, K. Plant Cell Physiol. 1972, 13, 385.

2. Ruediger, W.; Benz, J.; Lempert, U.; Schoch, S.; Steffens, D. Z. Pflanzenphysiol. 1973, 80, 131.

3. Muraja-Ljubicic, J.; Wrischer, M.; Ljubesic, N.; Naturforsch, Z.C. J. Biosci. 1999, 54, 333.

Bull. Chem. Soc. Ethiop. 2009, 23(2) 
4. Zaza, F.S.; Guedira, S.; Zaydoun, M.; Saidi Idrissi, A.; Lautie et Romain, F. Can. J. Anal. Sci. Spectrosc. 2004, 49, 15.

5. Kertit, S.; Aride, J.; Srhiri, A.; Benbachir, A. et Etman, M. C.R. Acad. Sci. 1993, 317, 1399.

6. Kertit, S.; Chaouket, F.; Srhiri, A.; Keddam, M. J. Appl. Electrochem. 1994, 24, 1139.

7. Hay, P.J.; Wadt, W.R. J. Chem. Phys. 1985, 82, 470.

8. Becke, A.D. J. Chem. Phys. 1993, 98, 5648.

9. Lee, C.; Yang, W.; Parr, R.G. Phys. Rev. 1980, B37, 785.

10. Pople, J.A. Modern Theoretical Chemistry in Applications of Electronic Structure Theory, Vol. 4, Schaefer III, H.F. (Ed.), Plenum Press: New York; 1977; pp 11-12, 16-17.

11. Hehre, W.J.; Ditchfield, R.; Radom, L.; Pople, J.A. J. Am. Chem. Soc. 1970, 92, 4796.

12. Levine, I.N. Quantum Chemistry, Prentice Hall: Englewood Cliffs, New Jersey; 1991; pp 594-595.

13. Feller, D.; Davidson, E.R. Rev. Comput. Chem. 1990, 1.

14. Davidson, E.R.; Feller, D. Chem. Rev. 1986, 86,681.

15. Helgaker, T.; Taylor, P.R. Modern Electronic Structure Theory, Part II, Yarkony, D. (Ed.), World Scientific: New York; 1995.

16. Gaussian Basis Sets on the web: http://www.emsl.pnl.gov/forms/ basisform.html.

17. Frisch, M.J.; Trucks, G.W.; Schlegel, H.B.; Scuseria, G.E.; Robb, M.A.; Cheeseman, J.R.; Zakrzweski, V.G.; Montgomery, J.A.; Stratmann, R.E.; Burant, J.C.; Dapprich, S.; Millam, J.M.; Daniels, A.D.; Kudin, K.N.; Strain, M.C.; Farkas, O.; Tomasi, J.; Barone, V.; Cossi, M.; Cammi, R.; Mennucci, B.; Pomelli, C.; Adamo, C.; Clifford, S.; Ochterski, J.; Petersson, G.A.; Ayala, P.Y.; Cui, Q.; Morokuma, K.; Malick, D.K.; Rabuck, A.D.; Raghavachari, K.; Foresman, J.B.; Cioslowski, J.; Ortiz, J.V.; Stefanov, B.B.; Liu, G.; Liashenko, A.; Piskorz, P.; Komaromi, I.; Gomperts, R.; Martin, R.L.; Fox, D.J.; Keith, T.; Al-Laham, M.A.; Peng, C.Y.; Nanayakkara, A.; Gonzalez, C.; Challacombe, M.; Gill, P.M.W.; Johnson, B.G.; Chen, W.; Wong, M.W.; Andres, J.L.; Head-Gordon, M.; Replogle, E.S.; Pople, J.A. Gaussian 98 (Revision A.1), Gaussian Inc.: Pittsburgh, PA; 1998.

18. Palmer, M.H.; Christen, D. J. Mol. Struct. 2004, 705, 177.

19. Potapov, V.; Tatarintchik, S.; Chimie Organique, Mir Publisher: Moscow; 1981.

20. Joffre, J.; Lerner, D.A.; Geneste, P. Bull. Soc. Chim. Belg. 1984, 93 , 831.

21. Bart, J.C.J.; Giordanov, N. Gaz. Chim. Ital. 1979, 109, 73.

22. Bart, J.C.J., Ragaini, V.; Proceedings of the Climax Third International Conference on the Chemistry and Uses of Molybdenum (Barry, H.F.; Mitchell, P.C.H. (Eds.), Climax Molybdenum Co.: Ann. Arbor, Michigan; 1979.

23. Xia Dong, Xu; Allen, C.S.; Chuang, C.-L.; Canary, J.W.; Acta Crystallographica Section C, Crystal Structure Communications 1998, 54, 600. 